\title{
Disputas por la educación superior intercultural en escenarios de conflicto. El caso de Guerrero, México $^{1}$
}

\author{
Paola Vargas Moreno \\ Universidad Nacional Hutónoma de México, Ciudad de México, México \\ paolakahlo@gmail.com
}

\begin{abstract}
RESUMEN
México cuenta con un sistema de Universidades Interculturales construidas «desde arriba» (desde el Estado) que, tras diez ańos de implementación, presenta limitaciones importantes derivadas del indigenismo estatal hegemónico. Como alternativa, han emergido experiencias «desde abajo» (desde los pueblos indígenas) para construir una educación superior contrahegemónica y autónoma, más cercana a las necesidades locales; empero, el financiamiento y legalidad de estos procesos, los coloca en una encrucijada que signa sus relaciones (negociaciones-conflictos) con el Estado. Este escenario de disputa se complejiza aún más cuando los territorios en donde se materializan los proyectos son escenarios de conflicto entre Estado, partidos políticos, guerrillas locales, narcotráfico y formas de justicia propia-comunitaria, como sucede en el caso del Estado de Guerrero, México.

En este marco, el presente documento I) da cuenta de cómo se ha consolidado la disputa por el ser y el deber ser de la Educación Superior Intercultural en Guerrero II) coloca como variable la relación de las experiencias con el contexto de violencia local y III) demuestra la insuficiencia de la dicotomía «desde arriba» vs. «desde abajo», todo ello con base en el análisis de los orígenes y trayectorias de dos universidades interculturales locales.
\end{abstract}

Palabras clave: Educación superior, educación superior intercultural, Guerrero (México), violencia, «desde arriba» vs «desde abajo»

\section{Dispute for the higher intercultural education in conflict scenes. Guerrero case, Mexico}

\begin{abstract}
Mexico possess a system of Intercultural Universities built "from the top» (of the government) that after ten years of implementation presents important limitations derived from the hegemonic state indigenism. As an alternative, education experiences have emerged «from below» ( from the indigenism people) to build a counterhegemonic and autonomous higher education , closer to the local necessities, however financing and legality of these process put them in a juncture that mark their relations (conflict- business) with the government. This dispute scenario becomes even more complex when the territories where this projects take place are conflict scenarios between the government, political parties, local guerrillas, drug trafficking and different forms of the own local community justice, as it is in the Guerrero area in Mexico.

In this context, this document: I) show us the way the dispute has been increase in relation to the reason

$1 \quad$ El presente documento hace parte de las reflexiones presentadas en el III Congreso Internacional Educación y Universidad para la Transformación Social. A 100 años de Córdoba, realizado del 21 al 23 de mayo del 2018 en la Universidad Nacional de Educación del Ecuador (UNAE) bajo el mismo título.
\end{abstract}


and the duty of the Intercultural Higher Education, in Guerrero. II) It places as a variable, the relation of the experiences with the local violence context and, III) it shows the lack of dichotomy "from the top» vs, «from below», all of this considering the creation and development of two local intercultural universities.

KeYwords: Higher education, intercultural higher education, Guerrero (Mexico), violence, «from the top» vs, «from below»

\section{Introducción}

En América Latina, de maneras múltiples, dinámicas y complejas, desde finales de la década de los ochenta la interculturalidad se ha venido consolidando como modelo hegemónico de administración de la diferencia, proyecto que supondría el reconocimiento de epistemes, historias y valores propios (de poblaciones étnico-culturalmente diferenciadas, predominantemente indígenas) en un diálogo horizontal con la cultura nacional (blanco-mestiza, no indígena). El modelo intercultural supone una educación ya no para los indígenas si no desde y con los indígenas, en donde comunidades y organizaciones participen activamente por la transformación de las realidades locales y el logro de su bienestar colectivo; no obstante, estas suposiciones se encuentran con una realidad compleja en donde las definiciones y los contenidos sobre el ser y el quehacer de la interculturalidad se disputan entre las políticas públicas del Estado, los proyectos e intereses de comunidades y organizaciones indígenas y el devenir cotidiano que coloca en el campo actores múltiples con intereses diversos en relación al contexto (iglesias, ONGs, comunidades académicas, entidades de cooperación internacional, etc.). Este escenario de disputa se complejiza aún más cuando los territorios en donde se materializan las apuestas de uno u otro sector se caracterizan por ser escenarios de violencia y conflicto entre Estado, partidos políticos, guerrillas locales, narcotráfico y formas de justicia propia y comunitaria, como sucede en el caso del Estado de Guerrero, México.

Así, en el presente artículo busco i) dar cuenta de cómo se ha consolidado la disputa por el ser y el deber ser de la Educación Superior Intercultural en Guerrero, México ii) colocar como variable la relación de las experiencias con el contexto de violencia local, y iii) demostrar la insuficiencia de la dicotomía "desde arriba» vs. "desde abajo», todo ello con base en el análisis de los orígenes y trayectorias de la Universidad de los Pueblos del Sur (UNISUR), institución creada "desde abajo», y la Universidad Intercultural del Estado de Guerrero (UIEG), institución parte del sistema nacional de Universidades Interculturales.

Para ello, en primera instancia, se presentarán algunos referentes teóricos que explican la dicotomía "desde arriba» vs «desde abajo» y argumentan la selección de las unidades de análisis, en un segundo momento se expondrán algunos referentes históricos sobre el contexto en donde se desarrollan las iniciativas, un tercer apartado 
dará cuenta de las trayectorias entrelazadas de la UNISUR y la UIEG y, finalmente, se situarán algunas (im)posibilidades y potencialidades de las experiencias para cerrar el documento y abrir la discusión.

Las reflexiones propuestas hacen parte de la investigación doctoral en curso «Educación Superior Intercultural: proyectos en disputa. Ecuador y México en comparación", propuesta investigativa de carácter analítico-cualitativo que mantiene como método un «estudio de caso múltiple (integrado)»(Yin, 2003) que implica el acercamiento a una pregunta empírica a partir de múltiples unidades de análisis dentro de un mismo caso (casos dentro de un caso), la integración de diferentes subunidades de análisis para la comprensión de cada unidad y el establecimiento de similitudes y/o diferencias entre unidades que permitan resolver la pregunta y elaborar generalizaciones teóricas.

De manera específica, las afirmaciones y debates inconclusos presentes en estas páginas, se nutren de la revisión de la literatura y la legislación correspondientes y un ejercicio amplio de observación-acción participativa logrado en el ejercicio como docente en la sede de Santa Cruz del Rincón durante el año 2016, más un ejercicio de acompañamiento informal durante el primer semestre del 2017.

\section{Referentes teóricos y excusas metodológicas: «desde arriba» vs. «desde abajo»}

Atendiendo a la propuesta de análisis planteada por Luis Enrique López-Hurtado (2009) en el ámbito de la Educación Intercultural Bilingüe, para diversos casos latinoamericanos y con especial énfasis en las experiencias andinas, propuesta retomada y desarrollada como modelo analítico para el caso mexicano por Maria Bertely (Bertely, 2011; Bertely, et al., 2013), es posible afirmar que los proyectos y experiencias de Educación Superior Intercultural en América Latina pueden distinguirse por sus particulares locus de enunciación, por sus propios puntos de partida y/o direccionalidades: «desde arriba", los proyectos son diseñados, implementados y, por ende, financiados, desde los Estados para dar atención a las necesidades de pueblos y comunidades étnicamente diferenciadas, especialmente para pueblos y comunidades indígenas, como respuesta ante las presiones históricas de las organizaciones, respuesta lograda a pulso entre conflictos y negociaciones. «Desde abajo», los proyectos y experiencias son sońados y diseñados desde las propias comunidades y organizaciones indígenas que, junto con aliados estratégicos, logran implementar y sostener experiencias más cercanas y pertinentes a las realidades locales en un afán por consolidar una educación superior propia, contrahegemónica y autónoma.

"Desde arriba» los Estados han trabajado en resolver el problema de la Educación Superior para indígenas y afrodescendientes a través de estrategias diversas que van des- 
de políticas de acción afirmativa —inclusión de individuos y/o creación de proyectos y programas conducentes a títulos en Instituciones de Educación Superior "convencionales» (Mato, 2015) — hasta la creación de Instituciones de Educación Superior Intercultural estatales. Esta direccionalidad supone un punto de partida específico, una posición particular, un «desde afuera» que, a pesar de los esfuerzos, ha sido insuficiente y no ha logrado canalizar de manera efectiva las demandas de las poblaciones indígenas.

Problemas como el acceso y la cobertura, la pertinencia y el vínculo con las comunidades, los contenidos curriculares entre el diálogo de saberes y el epistemicidio, el racismo emergente en las prácticas tanto burocrático-institucionales como de enseńanza-aprendizaje, entre otros, son asuntos sin resolver y la literatura de la última década apunta a que esta incapacidad se deriva de la permanencia recia de un proyecto de Estado liberal (mononacional-monocultural), de una alianza entre este proyecto de Estado y el proyecto de desarrollo capitalista en su etapa neoliberal contemporánea $y$, en consecuencia, de la continuidad de una agenda indigenista en el diseño de la política pública y de un sistema de educación superior homogéneo y homogenizante que permiten la estructuración (producción y reproducción) de estos dos proyectos en connubio. Esta permanencia supone la no participación de las comunidades y organizaciones indígenas en el diseño de la política pública educativa, el desdibujamiento y consecuente ausencia de la agenda indígena en el proyecto estatal.

"Desde abajo», la mayoría de las veces ante la ausencia del Estado, algunas otras ante la consigna explícita de querer permanecer por fuera de éste, se han gestado diversas formas de organización desde lo comunitario, en los intersticios de la alianza Estadocapital, más allá del diseño hegemónico de política educativa. Esta direccionalidad también supone un punto de partida específico, una posición particular, un «desde adentro" desde donde comunidades y organizaciones deciden de manera consensuada el ser y el quehacer de la educación superior requerida y deseada, ubican aliados de manera contingente y desarrollan experiencias variadas, flexibles y creativas, en donde la posición política e ideológica es explícita pues se pretende actuar de manera igualmente explícita contra el sistema educativo hegemónico que las ha negado, invisibilizado y/o subalternizado.

En este mismo sentido, se han consolidado dos diferentes «tipos ideales» de interculturalidad: uno que instituye una interculturalidad apolítica y armónica, celebrante, funcional, integracionista y conservadora, que responde a la forma Estado y sirve bien al capital; otra, que reconoce la interculturalidad como un escenario en permanente construcción, dinámico, político y conflictivo, como una necesidad crítica y una alternativa de ruptura, como una apuesta que debe ser recuperada como herramienta para la emancipación (Viaña, 2009; González \& Rojas, 2013; entre otros).

En esta instancia es preciso aclarar que uso la dicotomía «desde arriba» vs. "desde abajo» solo de manera ilustrativa pues considero que es una propuesta insuficiente que 
parte de la esencialización de estos dos lugares de enunciación y niega el protagonismo que pueden adquirir otros actores en la configuración del campo. Por ahora, i) insisto en el empleo de esta diferenciación en tanto que me sirve como excusa para establecer un mapa claro de la información que requiero recoger y analizar en mi proceso investigativo en marcha y ii) adelanto algunas reflexiones que pueden ir rompiendo la dicotomía y ensanchando los márgenes de análisis.

De este modo, tras una revisión de la literatura referente a las experiencias y el trabajo de acompañamiento y observación cercano a estas, puedo afirmar que la UIEG se caracteriza por i) su construcción «desde arriba», es decir, ser producto de los mandatos dictaminados desde la política pública diseñada para atender el problema de la educación superior para poblaciones indígenas en consonancia con políticas internacionales sobre Educación, Indígenas y Cultura, ii) su consecuente reconocimiento legal como parte del sistema de educación nacional y, por ende, su financiamiento estatal y/o federal, iii) sus propuestas atadas a la promesa de atender las demandas educativas de la población indígena en contexto ante tres necesidades centrales: educar a nińos y jóvenes indígenas, continuar con el proceso educativo en instancias de nivel superior y la resolución de estas dos en sus propios territorios, iv) sus discursos relacionados a la categoría interculturalidad como una propuesta educativa que busca incorporar al indígena / a lo indígena al desarrollo del país; es decir, la apropiación y uso del término interculturalidad para dotar de carácter alternativo, aunque conservador, a sus propuestas educativas.

Por su parte, la UNISUR se caracteriza por i) su construcción «desde abajo», es decir, su explicita relación con organizaciones sociales locales y comunidades indígenas que han reconocido históricamente al sujeto colectivo indígena como un actor en la construcción de su propia educación, ii) la alta conflictividad/tensión que mantienen con el Estado y las consecuencias observables de esta, iii) su explícito deseo de ser reconocidos por el Estado como parte del sistema de educación nacional en defensa de sus derecho como parte del Estado-nación, y iv) sus discursos y propuestas atadas a la categoría interculturalidad como una apuesta educativa que promete una ruptura con las prácticas de la educación superior convencional; es decir, la apropiación y uso del término interculturalidad para dotar de carácter reformista y esperanza de emancipación a nuevas apuestas educativas.

\section{Guerrero Bronco:}

\section{violencia, poblaciones y luchas indígenas en el Estado de Guerrero}

México es una república federal con una vasta riqueza étnica, lingüística y cultural. A nivel legislativo, en 1990 ratifica la adopción del Convenio 169 sobre pueblos indígenas 
y tribales de la OIT; en 1992 incluye en su Carta Constitucional el reconocimiento de los pueblos indígenas y la composición multicultural de la nación; y finalmente, en 2001, incluye el derecho a la libre determinación y la autonomía de los pueblos indígenas y el incremento de una educación bilingüe e intercultural. En su territorio, además de la alta concentración de población blanco-mestiza, habitan comunidades negras (afromexicanas), un porcentaje creciente de migrantes internacionales y entre 62 y 68 pueblos indígenas (entre 6 y el 13\% de la población para el 2010). Es difícil determinar el número preciso de población indígena en México pues el último censo nacional (Censo de Población y Vivienda del 2010) realizado por el Instituto Nacional de Estadística y Geografía (INEGI) cuenta con tres criterios diferenciados para ubicar la población indígena, tres criterios que han arrojado datos diferentes ${ }^{2}$. Al no contar con números precisos respecto a la población indígena, se dificulta conocer las dimensiones reales de los diversos problemas que atañen a los pueblos indígenas; entre ellos, el problema de la educación superior.

En referencia a nuestro caso de análisis, el Estado de Guerrero cuenta con 3.533.251 habitantes, de los cuáles 456.774 ( 5 años y más), hablan lenguas indígenas, lo que representa un poco menos del $15 \%$ de la población total. No obstante, al sumar los datos de la población indígena por autoadscripción, la cuenta arroja un total de 635.620 indígenas, lo que equivale al 18.75\% de la población del Estado (INEGI, 2010). El Estado está configurado por siete diversas regiones socioculturales determinadas por los asentamientos ocupados históricamente por comunidades y pueblos indígenas (Mephaa o tlapanecos, Nu Savi o mixtecos, Noom daà o amuzgos y Naua o Nahualtl de Guerrero), afromexicanos y mestizos. En este marco, Guerrero se caracteriza por ser uno de los Estados con mayor población indígena de México y ser, después de Chiapas y Oaxaca, el Estado más pobre, con menor promedio de escolaridad y mayor promedio de analfabetismo en todo el país (INEGI, 2010).

La historia de Guerrero ha estado marcada por el despojo, la pobreza, la violencia y la represión estatal. Así, como necesaria reacción y contrapunto, esta historia también se caracteriza por una importante organización social y lucha de carácter campesino e indígena por la tierra, la educación, la autonomía, la justicia y la dignidad.

La lucha gestada en Guerrero ha adquirido formas diversas desde sus orígenes hasta hoy: ante las evidencias que permitían develar que los impactos de La Revolución

2 De una parte, ubica a la población de 5 años y más hablante de lengua indígena (criterio de vieja data en los censos mexicanos); este criterio arroja como resultado 6.695 .228 habitantes ( 3.287 .839 hombres, 3.407 .389 mujeres) que equivale al 6\% de la población total estimada para el 2010. Un segundo criterio, ubica a la población en hogares censales indígenas, que corresponde al total de personas que forman hogares donde el jefe del hogar o su cónyuge hablan alguna lengua indígena; a saber, 10.788.615 de habitantes, el 9,5\%. Finalmente, una tercera modalidad, cada vez más presente en América Latina, ubica a la población de 3 años y más según condición de autoadscripción étnica; para este caso, 15.703 .474 de habitantes se han identificado en esta categoría (7.618.523 hombres, 8.084 .951 mujeres) equivalente al $13 \%$ del total nacional. 
(1910) no habían transformando realmente las estructuras de acumulación de capital y el ejercicio del poder en Guerrero, ya desde los comienzos de la segunda mitad del siglo $\mathrm{xx}$, profesionales, estudiantes y campesinos guerrerenses conformaron sindicatos rojos y ligas agraristas que, ante los oídos sordos y la mano dura del Estado, radicalizaron sus acciones y transformaron sus estrategias de lucha, unos a través de la conformación de guerrillas como la Asociación Cívica Nacional Revolucionaria (ACNR, 1963) con la firme intención de tomar el poder a través de las armas, otros a través de la configuración de agrupaciones más amplias, como el Consejo de Pueblos de Montaña (1979) en alianza con el Partido Comunista y el Movimiento Magisterial, quienes mantenían el eje de sus luchas en los ámbitos sindical-agrario y sindical-educativo (Bartra, 1996; Domínguez, 2015).

Las experiencias acumuladas hasta la década de los ochenta, la influencia creciente de la teología de la liberación, la ausencia de un Estado que garantizara el ejercicio libre y pleno de derechos, el reconocimiento de un sinnúmero de falencias del indigenismo hegemónico desde donde se hacía la política pública estatal de espalda a las necesidades y realidades de los pueblos indígenas, y una tendencia regional de re-etnificación del campesinado a partir del reconocimiento de su origen indígena, posibilitaron la reconfiguración y ampliación de las luchas en donde la tierra y la educación, entre otras banderas, fueron re-articuladas en clave étnica india siendo entonces la reivindicación de los derechos indígenas el nuevo derrotero de acción; la lengua, los usos y costumbres, la relación diferenciada con la naturaleza y la denuncia del colonialismo histórico, serán parte transversal de los nuevos códigos de lucha. La creación del Consejo 500 Años de Resistencia India, Negra y Popular en 1991, como parte del programa para denunciar los 500 años de colonialismo y articular la lucha indígena nacional y regional, da cuenta de ello. El Consejo Guerrerense hizo parte activa de este proceso.

A las denuncias por tierra (propiedad colectiva, usos, accesos, producción, distribución) y educación (educación propia, educación bilingüe, lengua, cultura), se fueron sumando reclamos por el reconocimiento de formas de gobierno y justicia propia. Estas nuevas demandas emergían no solo ante la violencia padecida por las comunidades de parte del Estado (violencia estructural por el control de los procesos productivos que los condenaba a la pobreza y les imposibilitaba el ejercicio de derechos, sumada a la represión y violencia física parte de las políticas de contrainsurgencia implementadas para atacar los fuerzas organizadas); sino, también, ante la creciente oleada de delincuencia que azotaba la región y la emergencia y consolidación del narcotráfico, fenómenos derivados de décadas de violencia estructural y una evidente crisis institucional y del sistema de justicia estatal (López, 2015).

En este contexto, el proceso nacional en torno a los 500 años y la participación del Consejo Guerrerense en las mesas de trabajo, catapultó la creación del Consejo de Autoridades Indígenas (CAIN) en 1994, espacio que dio forma a la Coordinadora 
Regional de Autoridades Comunitarias - Policía Comunitaria (CRAC - PC), también conocida como Sistema Comunitario de Seguridad, Justicia y Reeducación de la Costa Chica y Montaña de Guerrero (SCSJR).

En un inicio, ante la ausencia del Estado y el recrudecimiento de la inseguridad en la zona (robos, abigeatos, asaltos y violaciones sexuales), las comunidades decidieron organizarse y tomar acciones para colocar freno a la situación: comenzaron a sumar voluntarios y rotar su sistema tradicional de cargos para cumplir funciones de impartición de justicia y reeducación, fungir como policías en autodefensa de su comunidad. No obstante, con el paso de los ańos, los problemas ya no serían los mismos: de un lado, la presencia del narcotráfico incrementó de manera súbita ${ }^{3}$, al igual que las concesiones para minería ${ }^{4}$ y la agenda se ampliaría para hacer frente a los impactos de estos problemas en agudización en sus comunidades, impactos auspiciados por las alianzas cada vez más indudables entre narcotraficantes, empresas transnacionales mineras y Estado Federal (Tlachinollan, 2004, 2016; López, 2015; Domínguez, 2015; Registro de campo, 2016).

Como se hace evidente, la violencia en Guerrero se ha vivido -y se vive aún- de formas múltiples y con múltiples implicaciones. Hasta el día de hoy, persiste la violencia de Estado (tanto la estructural como la contrainsurgente) ahora aderezada por las renovadas relaciones del Gobierno del Estado, persiste la delincuencia y se ha robustecido el crimen organizado en contra de la organización social, el narcotráfico va en crecimiento (tanto por sus renovados vínculos con el Estado y el fortalecimiento de su ejército que ha ganado presencia a lo largo y ancho del territorio, como por consolidarse como una posibilidad real de producción y reproducción de la vida material de las poblaciones ante la pobreza y el desempleo); además, en honor a la verdad, las relaciones entre estos focos de violencia y las fuerzas locales organizadas que los han querido combatir, han generado más violencia, a pesar de sus intentos por construir alternativas de seguridad y justicia.

De manera paralela, la lucha por una educación propia se ha ido gestando al ritmo de los conflictos locales y la Educación Superior Intercultural va adquiriendo forma.

3 Según datos de la Secretaría de Defensa Nacional (SEDENA), Guerrero era el primer productor de amapola en el país para el año 2004 (En: Tlachinollan, 2004). Hasta el día de hoy, sigue encabezando los listados. Además, muchas de las rutas de paso para el traslado de insumos y mercancías desde/hacia los puertos del pacífico, se encuentran en este Estado.

4 Guerrero es uno de los Estados con mayor concentración de oro, plata y plomo del país. La arremetida neoliberal instituida con los candidatos del Partido Acción Nacional (PAN) en el poder (Vicente Fox 2000-2006 y Felipe Calderón 2006-2012) ampliaron de manera abrupta el número de concesiones mineras a empresas extranjeras y/o transnacionales en el país. En Guerrero, como en otros Estados, muchas de estas concesiones se han otorgado violentando el derecho de las comunidades al consentimiento libre e informado o haciendo de la minera el prestador de servicios ideal ante la ausencia de un Estado garante de derechos y proveedor de servicios básicos (Domínguez, 2015; Tlachinollan, 2016). 


\section{Disputas por la Educación Superior Intercultural en Guerrero. Trayectorias de la UIEG y la UNISUR}

A nivel nacional, con un acumulado de reivindicaciones históricas a favor de una educación propia, entre las cuáles se destacan las promovidas por la OPINAC ${ }^{5}$, y tras el levantamiento zapatista en 1994, de a pocos se va incluyendo en la agenda educativa nacional una educación superior pensada para y desde indígenas (cada vez más etiquetada como Educación Superior Intercultural) a través de diversos programas y proyectos de inclusión, de colaboración, de extensión, de formación autónoma- con características diversas arraigadas a las particularidades de cada grupo indígena en relación a los diferentes Estados y sus gobiernos.

Para el caso de Guerrero, la historia de la Educación Superior Intercultural podría remontarse a sus combativas y perseguidas normales rurales; no obstante, si bien estas se crearon para atender a las poblaciones indígenas en sus territorios desde mediados de la década de los veinte (Tlachinollan, 2015), atienden en el nivel de media y media superior y su carácter intercultural es relativo y casi dependiente de cada una de las experiencias (no es política pública -desde el Estado- o consigna colectiva -desde las comunidades $y / u$ organizaciones- afirmar que estos procesos representan experiencias interculturales), por ello, su historia no hace parte de mi actual investigación.

Como propuesta, siguiendo el modelo analítico sugerido por Bertely $(2011$, 2013), ( «desde arriba» vs. «desde abajo»), ubico como instituciones pioneras a la Universidad Intercultural del Estado de Guerrero (UIEG) en la primera categoría y la Universidad de los Pueblos del Sur (UNISUR), en la segunda. No obstante, las líneas precisas que separan la trayectoria una y otra se desdibujan, sobre todo si revisamos sus procesos de origen e institucionalización. Como veremos, la misma idea y el mismo proceso para la creación de una institución de educación superior para y desde los pueblos indígenas del Estado de Guerrero, da origen a ambas universidades, lo que da cuenta de las porosidades entre los diferentes lugares de enunciación.

La UIEG y la UNISUR nacen para atender las necesidades educativas y socio-económicas locales, teniendo como base los procesos de resistencia de los pueblos originarios, afros y campesinos de Guerrero en un afán por recuperar y fortalecer las formas de pensamiento y organización propias en un contexto amplio de desatención estatal. Sus fundamentos epistemológicos se sustentan en el reconocimiento de la matriz cultural

5 La Organización de Profesionistas Indígenas Nahuas A.C. (OPINAC) y la Alianza Nacional de Profesionales Indígenas Bilingües (ANPIBAC) -aunque esta última señalada por algunos por sus relaciones ambiguas con el Estado-, fueron organizaciones de profesionales indígenas pioneras que, para finales de la década de los setenta y comienzos de los ochenta del siglo XX, lograron consolidar una plataforma étnica que logró reunir cientos de maestros indígenas e instructores bilingües en diversos Encuentros Nacionales de Maestros Indígenas para pensarse una nueva forma de educación no colonizante, proponer una educación bilingüe bicultural como alternativa y transformar el indigenismo hegemónico Gutiérrez, 2012; Castillo, 2016). 
de los pueblos indígenas y afromestizos, en un diálogo constante con el pensamiento universal. Se proponen la recuperación del pensamiento indígena y la construcción de una sociedad intercultural a partir de la consolidación y desarrollo de un nuevo tipo de educación que parta del interior de las mismas comunidades y su tarea prioritaria está orientada hacia la formación de intelectuales que sean capaces, desde su propio universo y sustento cultural, de dar respuesta a los problemas locales y potenciar un desarrollo autogestivo, un modelo de desarrollo alternativo (UNISUR, 2006).

La propuesta académica es el resultado de un largo proceso de debate y sistematización en el que participó un equipo interdisciplinario conformado por comunidades, autoridades, intelectuales e investigadores indígenas, afros y mestizos de Guerrero en colaboración con docentes e investigadores de la Ciudad de México. Este proceso, que duró aproximadamente seis años, obtuvo como resultado un Estudio de Factibilidad (UNISUR, 2006) que trazaba el camino que daría vía institucional a la universidad. El proceso se adelantó tanto por el interés de pueblos y comunidades, enmarcado en la lucha por una educación superior propia, como por los aires de oportunidad de la época, pues la Coordinación General de Educación Intercultural y Bilingüe (CGEIB) de la Secretaría de Educación Pública (SEP) comenzaba su funcionamiento, y con este, la institucionalización de Universidades Interculturales con presupuestos del Estado.

Una comisión académica, conformada por intelectuales indígenas y no indígenas, de Guerrero y de Ciudad de México, se dio a la tarea de compilar y sistematizar la información necesaria para la apertura de la institución en Santa Cruz del Rincón, municipio de Malinaltepec. El Estudio tuvo eco en los oídos del gobierno nacional de marcado corte neoliberal, encabezado en aquel entonces por Vicente Fox, en las oficinas de la CGEIB con Lourdes Casillas y Sylvia Schmelkes a la cabeza, y en los pasillos del gobierno estatal, con Zeferino Torreblanca del Partido de la Revolución Democrática (PRD) en arribo. Las expectativas eran altas y no tardaron en presentarse desacuerdos, rupturas y traiciones tanto dentro de la Comisión como entre esta y las entidades del Estado y la Federación con las que se venían estableciendo negociaciones. En palabras de Floriberto González, miembro de la Comisión Académica en aquel entonces, no tardó en levantarse «la jauría política detrás del proyecto [...] El pastel estaba a la vista y se abalanzaron sobre él» (González, 2017: 215).

Así, a pesar de la amplia participación y apoyo de comunidades y organizaciones, entre estas la CRAC-PC en crecimiento quien participaba de manera protagónica pues se hermanaba con la apuesta por una educación para la transformación ${ }^{6}$, tras congre-

6 La propuesta inicial de la CRAC-PC se anclaba en la reeducación como estructura del sistema de justicia comunitario. La reeducación supone la ausencia de penalidades a través de castigos y la presencia de procesos de enseńanza para la reinserción social a través de servicio a la comunidad; así, las sanciones conllevan detenciones temporales, pagos de multas, reparaciones, decomisos y, en mayor medida, servicio a los afectados y/o a la comunidad (Domínguez, 2015; López, 2015). 
sos y foros locales para difundir y lograr acuerdos sobre la propuesta de una universidad desde y para los pueblos de Guerrero, en el momento de la decisión final, los dineros presupuestados por el heraldo público fueron invertidos para la creación de la UIEG (2006), institución parte del sistema nacional de Universidades Interculturales de la CGEIB, ubicada en la comunidad de La Ciénega, también en el municipio de Malinaltepec. Según denuncian hasta hoy los miembros fundadores de la UNISUR, de una u otra forma se usurpó gran parte del trabajo de difusión y legitimación adelantado por la Comisión y su equipo, pues no se estaba respondiendo a cabalidad a la propuesta construida en colectivo en tanto que no se respetaban los fundamentos, objetivos y diseños curriculares y pedagógicos del proyecto original, no se integraban a las comunidades, académicos y organizaciones vinculadas en el proceso de base y se erigía una institución como bastión del Estado para interrumpir la avanzada organizativa desde y para las comunidades (Flores, 2016; González, 2017). Ante esta situación, señalada como alta traición por quienes venían adelantando el proceso, se separaron los caminos de la UIEG y la UNISUR. Una propuesta soñada y diseñada ampliamente «desde abajo», es partida en dos.

El 26 de mayo de 2007, en el marco del Tercer Congreso Estatal de Educación Intercultural realizado en la comunidad de Santa Cruz El Rincón, se creó la Universidad Intercultural de los Pueblos del Sur (UNISUR) por mandato de las autoridades civiles y comunitarias de los pueblos indígenas y afromestizos del Estado (Acta de Congreso. 26 de mayo de 2007). Desde entonces, es mandato de las comunidades suscritas al proyecto, la búsqueda del reconocimiento legal de la UNISUR ante el Estado como una forma de hacer efectivo el derecho a la educación para las poblaciones indígenas y afromexicanas de Guerrero. En 2012, con el fin de deslindarse explícitamente del proyecto oficial de interculturalidad, la institución cambia su nombre a Universidad de los Pueblos del Sur (Acta de Sesión Extraordinaria COEPES. 2 de julio de 2012).

Con el fin de lograr legalidad ante el Estado, la UNISUR ha promovido encuentros con diversos estamentos locales (el Gobierno del Estado, la Secretaría de Educación y el Congreso) y nacionales (la administración del Poder Legislativo del Gobierno Federal, la Cámara de Senadores y la SEP), pero los resultados no han sido los deseados. Sin embargo, y en contraste, es interesante ver cómo a nivel local, cada sede adelanta vínculos particulares con los gobiernos locales, así como con los partidos políticos de turno.

Además, para lograr el registro de las carreras ante la SEP y la legalización de sus títulos, se creó el Convenio General con la Universidad Autónoma de la Ciudad de México (UACM) en el 2008, marco legal que posibilitó la firma del Convenio de Incorporación y Reconocimiento de Validez de Estudios de la UNISUR con la UACM en 2015, tras años de arduo trabajo conjunto. Desafortunadamente, tras dos años de la firma, la relación se fracturó por motivos que van desde la falta de cumplimiento cabal 
con requisitos burocráticos de parte de la UNISUR y negligencia durante el primer año del Convenio de parte de las dos instituciones, hasta el ejercicio de un soterrado racismo de parte de un sector importante de funcionarios y docentes de la UACM en desacuerdo con el proceso (Registro de campo, 2016).

La UNISUR cuenta con un Tronco Común y cuatro licenciaturas: Cultura, lengua y memoria; Gestión ambiental comunitaria; Gobierno de municipios y territorios; y Justicia y derechos humanos. Durante un corto período la universidad contó con una licenciatura en Salud Comunitaria, pero no fue posible darle continuidad. Las diferentes licenciaturas se han impartido en ocho diferentes Unidades Académicas ${ }^{7}$. Según datos de la Comisión de Registro Escolar de la UNISUR, para septiembre de 2015 se contaba con un registro de 376 estudiantes (entre egresados y activos) con 88 bajas verificadas. No obstante, desde adentro, es fácil evidenciar que hay un problema importante de deserción escolar que disminuye significativamente estos números.

Igualmente, desde adentro, es innegable el esfuerzo que realizan tanto estudiantes como docentes por adelantar sus clases en contextos definitivamente precarios. Los docentes, la gran mayoría provenientes de Ciudad de México, participan de manera solidaria (gratuita) y costean su movilidad. Los estudiantes, en muchas de las sedes, juntan dinero para las comidas de todos los participantes y apoyan dando hospedaje a los profesores. Las decisiones dentro de las sedes son consensuadas de manera deliberativa y horizontal (aunque esto haga los procesos muchas veces lentos y difíciles de interconectar) y se respira, realmente, una voluntad de transformación. No obstante, al parecer esto no es suficiente; las comunidades y las organizaciones, incluso la CRAC-PC aún esperan que sus jóvenes tengan un título universitario certificado por la SEP (Registro de campo, 2016).

Por su parte, la UIEG inició trabajos en 2007 en La Ciénega (Malinaltepec) atendiendo a los arreglos entre fundadores y comunidad, quien había donado los terrenos; no obstante, son amplias las críticas que ha recibido este espacio por no cumplir con los requisitos mínimos para consolidar una institución universitaria de carácter estatal (servicios básicos como alimentación, hospedaje, transporte, comunicación, electricidad y agua suficientes) (González, 2017). Contó con su matrícula más alta en el 2012 (529 estudiantes) tras la apertura de una segunda sede en Ayutla de los Libres; no obstante, entre 2013 y 2015 se presentó una disminución importante en la matrícula (Aguirre, 2015). La UIEG cuenta con un programa especial de formación básica, que permite el egreso de Técnicos Superiores, y cinco licenciaturas: Lengua y cultura, Turismo alternativo, Ingeniería forestal, Gestión local y gobierno municipal,

7 Xochistlahuaca (Mpio. Xochistlahuaca), Xalitla (Mpio. Tepecuacuilco), Cacahuatepec (Mpio. Acapulco), Metlatonoc (Mpio. Metlatonoc) y Santa Cruz El Rincón (Mpio. Malinaltepec) -hoy (marzo 2018) cerradas- y -en funcionamiento, con sus bemoles-, Cuajinicuilapa (Mpio. Cuajinicuilapa), Hueycantenango (Mpio. José Joaquín de Herrera) y El Mesón (Mpio. Ayutla de los Libres). 
y Desarrollo Sustentable. Las dos primeras se vinculan con el desarrollo intercultural diseñado para la región, las carreras restantes "guardan relación con el desarrollo regional, sin embargo el campo del conocimiento genérico del programa no contempla de manera frontal al componente de la interculturalidad, es decir los programas podrian no responder a las necesidades de la comunidad inmediata» (Aguirre, 2015).

Parafraseando a Floriberto González (2017) rector de la UIEG (período 20132014), la universidad no ha cumplido con las expectativas de la comunidad, ha mantenido importantes falencias vinculadas a la composición y el compromiso de su equipo docente y al cambio recurrente de rectores por intereses políticos; con base en su análisis, en la UIEG, "se repite el modelo de las universidades convencionales... y mal» (González, 2017: 208).

En este mismo tenor, y hablando con una estudiante de la UNISUR, sede El Mesón, antigua estudiante de la UIEG, se reafirma la idea de que la promesa de interculturalidad que supone la UIEG, no es cumplida ante los ojos de las comunidades: "yo me salí porque decían que iba a ser diferente, pero no, era igual, no se hablaba de nuestros conocimientos indígenas como acá [en la UNISUR], era como en la prepa [...] además, hay profesores que no iban a clase y uno perdía mucho tiempo» (Estudiante UNISUR, El Mesón. Registro de campo. Julio, 2016). La sensación de fracaso e insatisfacción pareciera invadir también la experiencia de la UIEG.

\section{(Im) posibilidades y potencialidades}

Como he sugerido, la dicotomía "desde abajo» vs. "desde arriba» es insuficiente pues no da cuenta de las complejidades y dinámicas de las experiencias en contexto. En estricto sentido, considero que la mayoría de los proyectos y experiencias que se han pensado la educación para poblaciones indígenas nacen desde abajo, o por lo menos allí son sońadas inicialmente; no obstante, en la propia configuración del campo, asuntos centrales como el financiamiento, la institucionalidad, la legalidad y la legitimidad de los procesos, los coloca en una encrucijada que va dando forma tanto a sus relaciones (conflictos-negociaciones) con el Estado como al proyecto mismo que va logrando consolidarse en el tiempo. En este marco, si bien un diseño «desde abajo» supondría la participación y el consenso de organizaciones y comunidades para decidir sobre su devenir en el ámbito de la educación superior deseada y, en consecuencia, la superación o mejor resolución de los problemas permanentemente subrayados para las Instituciones de Educación Superior Intercultural diseñadas "desde arriba», las experiencias en el Estado de Guerrero pueden mostrar los bemoles de esta afirmación.

Los diversos intereses de índole político y económico que dan forma y contenido a las disputas por el proyecto de Educación Superior Intercultural en el Estado de 
Guerrero, dan cuenta de la violencia ejercida por parte del Estado hacia las organizaciones y comunidades indígenas de la región. En un principio, pensando en el momento de institucionalización de las propuestas, podríamos afirmar que esta violencia se ejerce como parte de las políticas de contrainsurgencia para la región, en tanto que se imposibilita la emergencia de la UNISUR como institución con reconocimiento y financiamiento estatal, desconociendo ańos de organización y lucha y, por ende, desconociendo a la organización social como sujeto colectivo de derechos. Miembros fundadores (Flores, 2016; González, 2017) y docentes aún en ejercicio en la UNISUR, coinciden en afirmar que a la UNISUR se le negó el reconocimiento pues «representaba un peligro para el Estado» en tanto que realmente le disputaba al Estado el monopolio de la educación para los pueblos indígenas en Guerrero; además se afirma que esto "había sido una decisión de Estado, ya que no se podia instalar dicha universidad en Santa Cruz del Rincón, por su antecedente de ser el origen de la Policía Comunitaria» (González, 2017: 226). Se puede pensar que la alianza orgánica original entre UNISUR y CRAC-PC, ha servido de excusa histórica para la no aprobación de la institución y la negación del derecho a una educación superior desde y para los pueblos indígenas.

La falta de reconocimiento y financiación ha colocado a la UNISUR en una encrucijada permanente que la obliga a reinventar contingentemente sus relaciones con entidades del gobierno local, partidos políticos, organizaciones y comunidades, muchas veces desatendiendo las necesidades o intereses de unos para aliarse con los otros.

Paralelamente, las imposibilidades para el desarrollo y consolidación de las dos experiencias, también se han vivido como parte de la violencia estructural que, si bien se teje desde este Estado, ha permeado la cotidianidad en Guerrero. La "política guerrerense», es decir, la forma particular de hacer política en Guerrero articulada por los juegos entre gobierno, partidos políticos, caciques locales y, muchas veces, organizaciones sociales (Domínguez, 2015; López, 2015; González, 2017), ha hecho tanto de la UNISUR como de la UIEG, botines políticos usados estratégicamente en diversos momentos; los vericuetos alrededor del origen de las experiencias da cuenta de esto, pero también se podrían subrayar los acercamientos del gobierno o los partidos políticos en momentos electorales, acercamientos que dan cuenta de la infraestructura de algunas de las Unidades Académicas en la UNISUR, por ejemplo (Registros de campo, 2016).

Estos devenires, no siempre tan transparentes ante los ojos de las comunidades, pueden explicar la pérdida de confianza, credibilidad y legitimidad de los procesos. Un ejemplo claro de esta pérdida es el incremento en la deserción escolar en ambas universidades. Aún es necesario ahondar en otros posibles motivos. Para el caso de la UNISUR, a esta situación se le suma la ausencia de reconocimiento legal en un contexto socio-cultural en donde la titulación representa una potencial salida laboral y, en consecuencia, movilidad social ascendente. 
De otra parte, y a pesar de las múltiples adversidades, es imperativo reconocer las potencialidades de los proyectos y las experiencias. Como proyecto, una universidad desde y para los pueblos, es una apuesta urgente no solo para el rescate y revalorización de los conocimientos propios, sino para la construcción de alternativas reales ante las necesidades locales desde sus propios protagonistas. Una apuesta de esta índole implica la ruptura radical con el ejercicio asistencialista que encubre el neo-indigenismo desde donde se piensa la Educación Superior Intercultural implementada "desde arriba», pero también los reflejos que se alcanzan a vislumbrar en la apuesta «desde abajo» en su búsqueda de institucionalidad, legalidad y reconocimiento. Los seis años de preparación que antecedieron la creación de las instituciones analizadas, dan cuenta de un trabajo de organización, discusión, planeación y seguimiento sin precedentes que es preciso revisar para saber qué tanta luz puede dar para el camino que aún falta por andar.

Como experiencia, la UIEG tiene como derroteros para explorar y consolidar sus potencialidades la institucionalidad, la legalidad y la financiación, tres características centrales para la consolidación de una apuesta universitaria de alta envergadura. Un ejercicio político y no politizado que permita reconocer los límites de la experiencia y el rediseño de la misma, puede bien aprovechar lo ganado para no morir como un «elefante blanco» (González, 2017, p. 250). Como experiencia, la UNISUR tiene como derrotero la solidaridad y el trabajo comprometido de la mayoría de sus docentes en ejercicio durante los últimos años, formas de organización interna que se esfuerzan por funcionar de manera democrática y horizontal, estudiantes y egresados -hombres y mujeres indígenas- que, a pesar de años de adversidades, aún siguen en la lucha por una educación superior diferente y trabajan por ella (Registros de campo, 2016). Como experiencias en marcha, ambas universidades se plantan en contextos álgidos de violencia en un intento por servir de opción "más allá de la migración, más allá del sicariato» (Joaquín Flores. Rector UNISUR. Registro de Campo. Julio 2016) pues ante la ausencia de oportunidades reales, es el narcotráfico la empresa que se ha venido consolidando como salida para la sobrevivencia y la reproducción de la vida misma. 


\section{Referencias}

Aguirre, M. (2015). Indicadores de Gestión de la Universidades Interculturales en México. Entrega I. México: CESOP - LXII Legislatura, Cámara de Diputados.

Bartra, A. (1996). Guerrero Bronco. Campesinos, ciudadanos y guerrilleros en la Costa Grande. México: Ediciones sinfiltro.

Bertely, M. (2011). Educación superior intercultural en México. Perfiles Educativos Vol. XXXIII. México: Instituto de Investigaciones sobre la Universidad y la Educación. 66-77.

Bertely, M., Dietz, G. \& Díaz, M. (Coord.) (2013). Estado del Conocimiento. Área 12. Multiculturalismo y Educación 2002-2011. México: ANUIES-COMIE.

Castillo, A. (2016). Reconstrucción histórico política de la educación indígena en México y los antecedentes no oficiales de la Universidad Intercultural del Estado de Hidalgo. En: Revista Mexicana de Investigación Educativa Vol. 21, Núm. 70, pp 691-717.

Domínguez, A. (2015). Resistencia, poder y conflicto en la construcción de la UNISUR y la Policía Comunitaria. Problemas entorno a la educación comunitaria en la Montaña de Guerrero. Tesis de Licenciatura. México: ENAH.

GonzÁlez, E. \& Rojas, A. (2013). Proyectos locales, autonomía educativa y resistencia indígena En: M. Bertely, G. Dietz \& M. Díaz (Coord.) Estado del Conocimiento. Área 12. Multiculturalismo y Educación 2002-2011 (pp. 273-298) México: ANUIES-COMIE.

GonzÁLez, F. (2017). La Universidad Intercultural del Estado de Guerrero; o la Travesía de un Proyecto Frustrado. En: F. González, F. Rosado-May \& G. Dietz. La gestión de la Educación Superior Intercultural en México. Retos y perspectivas de las universidades interculturales. Guerrero, México: Ediciones Trinchera.

Gutiérrez, N. (2012). Mitos nacionalistas e identidades étnicas. Los intelectuales indígenas y el Estado mexicano (2a. ed.) México: Instituto de Investigaciones Sociales, UNAM

López, L. (2015). Las potencialidades emancipatorias de un derecho no-estatal. El caso del Sistema Comunitario de Seguridad Justicia y Reeducación (Policía Comunitaria) de la Costa Chica y Montaña de Guerrero, México. Tesis de Doctorado. México: UNAM.

López-Hurtado, L. E. (2009). Interculturalidad, educación y política en América Latina: perspectivas desde el sur, pistas para una educación comprometida y dialogal. En: L.E. LópezHurtado (Ed.), Interculturalidad, educación y ciudadania: perspectivas latinoamericanas (pp. 129-220) Bolivia: Plural editores.

Mato, D. (2015). Pueblos indígenas, Estados y educación superior. Aprendizajes de experiencias en varios países de América Latina potencialmente útiles a los procesos en marcha en Argentina. En: Cuadernos de Antropología Social No 41. Argentina: Universidad de Buenos Aires.

Tlachinollan (2004). Décimo Informe. Centro de Derechos Humanos de la Montaña «Tlachinollan» A.C. Junio 2003-Mayo 2004. Tlapa, México. 
Tlachinollan (2015). Desde las trincheras de Ayotzinapa. La defensa por la educación y la vida de los hijos del pueblo. XXI Informe. Centro de Derechos Humanos de la Montaña «Tlachinollan» A.C. Junio 2014-Junio 2054. Tlapa, México

Tlachinollan (2016). JÚBA WAJIÍN. Una batalla a cielo abierto en la Montaña de Guerrero por la defensa del territorio y la vida. Tlapa de Comonfort, Guerrero: Tlachinollan Centro de Derechos Humanos de la Montaña - Fundación Heinrich Böll en México.

VIAÑA, J. (2009). Interculturalidad como herramienta de emancipación. Hacia una redefinición de la interculturalidad y sus usos estatales. Bolivia: Instituto Internacional de Integración, Convenio Andrés Bello.

YIN, Robert L. (2003). Case Study Research. Design and methods. United States of America: Sage Publicatios, Inc.

\section{Otros documentos referenciados}

Comisión Estatal para la Planeación de la Educación Superior (COEPES). Acta de Sesión Extraordinaria COEPES. Chilpancingo, Guerrero. 2 de julio de 2012

FLores, Joaquín (2016) UNISUR a tres fuegos. Documento de trabajo interno.

INEGI (Instituto Nacional de Estadística y Geografía) (2010). Censo de Población y de Vivienda. México.

Tercer Congreso Estatal de Educación Intercultural. Acta de Congreso. Santa Cruz EL Rincón, Malinaltepec, Guerrero. 26 de mayo de 2007.

Universidad de los Pueblos del Sur (UNISUR) (2006) Estudio de Factibilidad. 